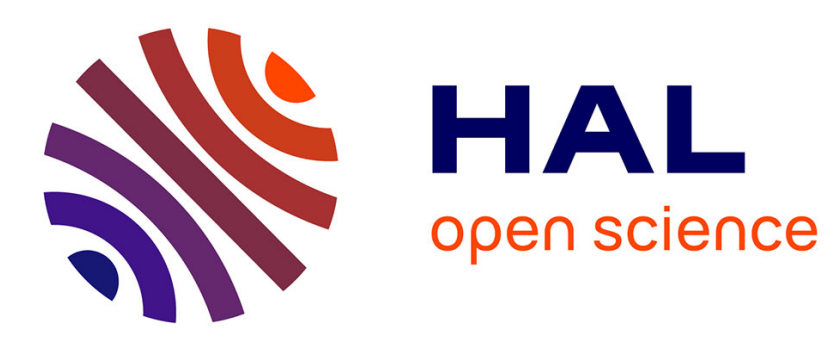

\title{
Gas turbine performance increase using an air cooler with a phase change energy storage
}

Jean-Pierre Bedecarrats, Françoise Strub

\section{To cite this version:}

Jean-Pierre Bedecarrats, Françoise Strub. Gas turbine performance increase using an air cooler with a phase change energy storage. Applied Thermal Engineering, 2010, 29 (5-6), pp.1166. 10.1016/j.applthermaleng.2008.06.004 . hal-00634761

\section{HAL Id: hal-00634761 \\ https://hal.science/hal-00634761}

Submitted on 23 Oct 2011

HAL is a multi-disciplinary open access archive for the deposit and dissemination of scientific research documents, whether they are published or not. The documents may come from teaching and research institutions in France or abroad, or from public or private research centers.
L'archive ouverte pluridisciplinaire HAL, est destinée au dépôt et à la diffusion de documents scientifiques de niveau recherche, publiés ou non, émanant des établissements d'enseignement et de recherche français ou étrangers, des laboratoires publics ou privés. 


\section{Accepted Manuscript}

Gas turbine performance increase using an air cooler with a phase change energy storage

Jean-Pierre Bédécarrats, Françoise Strub

PII:

S1359-4311(08)00269-X

DOI:

10.1016/j.applthermaleng.2008.06.004

Reference:

ATE 2539

To appear in:

Applied Thermal Engineering

\section{APPLIED}

THERMAL

ENGINEERING

$\begin{array}{ll}\text { Received Date: } & 7 \text { April } 2008 \\ \text { Accepted Date: } & 8 \text { June } 2008\end{array}$

Please cite this article as: J-P. Bédécarrats, F. Strub, Gas turbine performance increase using an air cooler with a phase change energy storage, Applied Thermal Engineering (2008), doi: 10.1016/j.applthermaleng.2008.06.004

This is a PDF file of an unedited manuscript that has been accepted for publication. As a service to our customers we are providing this early version of the manuscript. The manuscript will undergo copyediting, typesetting, and review of the resulting proof before it is published in its final form. Please note that during the production process errors may be discovered which could affect the content, and all legal disclaimers that apply to the journal pertain. 


\title{
Gas turbine performance increase using an air cooler with a phase change energy storage
}

Jean-Pierre Bédécarrats*, Françoise Strub

Laboratoire de Thermique, Energétique et Procédés, Université de Pau et des Pays de l'Adour,

Avenue de l'Université. BP 1155. 64013 Pau cedex. France.

Fax : (33) 559407725 Email : jean-pierre.bedecarrats@univ-pau.fr

* author to whom all correspondence should be addressed

\begin{abstract}
Gas turbine inlet air cooling improves its performance. Inlet air cooling process is studied including a phase-change refrigeration storage which consists in the use of a cylindrical tank filled with encapsulated Phase Change Materials (PCM). The Modelling of a plant is carried out and tested for a hot and wet climate (New Delhi in August). It makes it possible to design each component and to quantify the benefit of the use of a refrigeration storage.
\end{abstract}

\section{Keywords}

Cold storage; Liquid-solid Phase Change Material; supercooling; Gas turbine; Modelling.

\section{Introduction}

The gas turbines are engines often used to produce electricity. Their capacity and efficiency are really decreasing as ambient temperature is increasing. 
The possibility of improving the electric output by cooling the turbine inlet air was already studied with different air coolers $[1,2,3]$. The traditional solution is the direct mechanical refrigeration which consists in using a compression refrigerating machine to cool the air. This system presents the major disadvantage to consume electricity as the turbine capacity is lower i.e. during the hottest period of the day when the activity and thus the electric requirement often reach their maximum (on-peak hours). This consummation is parasitic power. The use of a refrigeration storage could be a solution since the supply and the consumption of energy will vary independently with time [4]. There are different ways to do thermal storage [5]: ice harvester, glycol chiller and ice tank, encapsulated phase change materials...

The inlet air-cooling process including phase-change refrigeration storage is studied. A plant made up of a gas turbine, an inlet air exchanger, a chiller and a storage tank filled with encapsulated phase-change materials has been designed with industrial components. The modelling of its operation is carried out and it allows us to design the refrigeration system for one given turbine when the climate and electric load are done versus time. It has been tested for a hot and wet climate (New Delhi in August). We present here the principle of the modelling as well as results for the operation of the unit under well-defined conditions

\section{Presentation}

\subsection{Presentation of the refrigeration storage system}

The present work is following upon former works $[6,7]$ on the study of a refrigeration storage system using phase change material encapsulated in spherical envelopes. These capsules called nodules have an outer diameter of $77 \mathrm{~mm}$ and are blow mould from a blend of polyolefins with an average thickness of $2 \mathrm{~mm}$. The nodules fill a cylindrical 
tank placed in a refrigeration loop. A chilled fluid (glycol water) circulates inside the tank through the nodules allowing heat exchange in the charge mode and the discharge mode.

\subsection{Principle and operating conditions of the studied installation}

The system whose operation has been modelled is defined from a marketed gas turbine. Turbine performance communicated by the manufacturer is introduced into the model. The exchanger, the refrigerating machine and the storage system are then dimensioned to ensure operation described by figure 1 . A hot and wet climate (New Delhi), very penalising for the refrigeration requirement, was selected in order to quantify the interest of the refrigeration storage.

Figure 1 shows the plant. During the charge mode (generally by night during the offpeak hours) the refrigerating machine is under operation and the glycol water is flowing through the tank with abcd direction in order to crystallise the PCM contained in the nodules. During the discharge mode, the water glycol flowing with bghefcb direction brings about the melting of the PCM. The stored cooling is thus recovered by the glycol water, which, by supplying the exchanger, makes it possible to cool the turbine inlet air.

The melting point of the PCM used here is $0^{\circ} \mathrm{C}$. The PCM is water.

It should be noted that during operation, the direction of the water glycol flow in the tank varies depending on whether it is the charge mode or it is the discharge mode. The tank is vertical and the fluid flows from the bottom to the top for the charge process and from the top to the bottom for the discharge process. 
Thus, the refrigerating machine is running only to charge the tank during the off-peak hours of the electric requirement. To cool the turbine inlet air, only cold from storage is required.

\subsection{Plant operation.}

The installation is led so that the turbine provides constantly the required electric output by cooling the ambient air before its input in the turbine when it needs to be. According to the power that must to be supplied by the turbine, inlet air temperature can be controlled by actuating the mixing three-ways valve (Figure 1). Thus the storage tank is partly by-passed to control the glycol water temperature at the inlet of the exchanger (in any case the temperature is limited to $0^{\circ} \mathrm{C}$ in order to avoid frost formation over the fins of the exchanger). The fluid flow rate in the exchanger remains constant while the one through the tank varies according to the electric requirement and the outside temperature.

\section{Summary of the previous works about refrigeration storage}

\subsection{Presentation}

The advantages of the used storage process are many and obvious [7]. The disadvantages result from the supercooling phenomenon. It is well state that liquid PCM does not crystallise at the melting point (solid-liquid equilibrium) but at a lower temperature. This phenomenon increases the cost of operation or investment. The main feature of crystallisation is its stochastic character : samples that are apparently identical will not transform at the same temperature and at the same time during the cooling process. This fact is easily explained by the conventional theory of nucleation [6], which gives the probability of crystallisation of a sample per unit of time. Nucleation 
theories explain that inside the liquid, the fluctuations create small aggregates which initiate the crystallisation if they have a size greater than a critical value depending on the temperature. In fact, the critical value is different if the aggregate forms inside the liquid (homogeneous nucleation) or on the surface of solid particles as nucleating agents, or simply on the interface of the liquid and the container (heterogeneous nucleation). So it is theoretically confirmed that where the heterogeneous nucleation is concerned the crystallization occurs at a higher temperature.

The first work has analysed the supercooling of the material $[6,7]$ while trying to reduce it by the addition of nucleating catalysts and by quantifying its influence on the process operation. The experimental installation, including a cylindrical tank of reduced size ( $1 \mathrm{~m}^{3}$ containing 2500 nodules)[7], made possible the thorough knowledge of the operation of this type of storage process. The influence of various parameters is shown. A numerical simulation of the process has been developed and proved from the measurements made on the experimental set-up [8]

\subsection{Modelling}

The numerical simulations, presented in several previous papers $[7,8]$, consider the aspects of both the surrounding heat transfer fluid and the phase change material packed inside the nodules in the charge mode as well as in the discharge mode. The chilled fluid is flowing vertically respecting the natural stratification due to the density of the coolant.

\subsubsection{Modelling the charge mode}

The tank is divided into several meshes containing N nodules. Applying the laws of conservation of mass and energy to each layer yields : 


$$
\rho c_{P f} V \frac{d T_{f}}{d t}=\rho c_{P f} q_{c}\left(T_{m}-T_{m+1}\right)+\sum_{i=1}^{N} \Phi_{i}
$$

where $T_{f}=\left(T_{m}+T_{m+1}\right) / 2$ is the average temperature of the heat transfer fluid of the layer ( $T_{m}$ and $T_{m+1}$ are respectively the inlet and the outlet temperature of the layer) and $\Phi_{i}$ is the flux exchanged by the nodule $\mathrm{i}$.

Even when the heat transfer fluid temperature is considered uniform in each layer, all the nodules of each layer do not simultaneously pass through the phase change at the melting temperature $T_{M}$ because of the supercooling and the erratic character of the crystallisation. The nodules can be in different states (non-crystallised, entirely crystallised or partly crystallised) according to their own value of the beginning of the crystallisation.

Applying the nucleation laws [6], the number of new crystallisations and the corresponding fluxes can be calculated at each time $\mathrm{t}$.

The quasistationary approximation [9] is applied to the determination of $\Phi_{i}$ during crystallisation.

PCM is water and the liquid phase of water is denser than the corresponding solid, so the PCM container must be made large enough to accommodate the solid during the crystallization part of a phase-change cycle. The incomplete filling of the nodules ( $96 \%$ of the free volume of the envelope) is taken into account [7].

Consider a nodule of inner radius $r_{i}$. Uniform cooling of its surface will result in a spherically symmetric crystallisation-front, $r=r_{s}(t)$ the inner radius of solid PCM, propagating inwards from $r=r_{i}$ with liquid at $T_{M}$ for $0 \leq r \leq r_{s}(t)$ and solid for $r_{s}(t) \leq r \leq r_{i}$. Assuming constant thermal properties in each phase, the steady-state 
solution of the heat conduction in the solid has the form ( $\theta$ is the temperature of the solid PCM):

$$
\theta(r, t)=T_{M}+\left[T_{f}(t)-T_{M}\right] \frac{1-\frac{r_{s}(t)}{r}}{\left(\frac{k_{s}}{k_{p}}-1\right) \frac{r_{s}(t)}{r_{i}}+\left(\frac{k_{s}}{h r_{e}}-\frac{k_{s}}{k_{p}}\right) \frac{r_{s}}{r_{e}}+1}
$$

The interface conditions here have the standard form :

$$
\rho_{s} L_{F} \frac{d r_{s}(t)}{d t}=k_{s}\left[\frac{\partial \theta(r, t)}{\partial r}\right]_{r=r_{s}(t)}=\frac{-\Phi_{i}}{4 \pi r_{S}^{2}(t)}
$$

The determination of $\Phi_{i}$ before crystallisation starts and after crystallisation is finished is done considering the uniform PCM temperature and it is possible to write that the internal energy variation in the PCM is equal to the flux that leaves the nodule.

The heat transfer coefficient between the nodule and the fluid is determined by a correlation type $N u=f(R e, P r)$ and so are depending on the flow rate and on the fluid temperature.

\subsubsection{Modelling the discharge mode}

Supercooling occurs only upon crystallisation but never upon melting. So, all the nodules from each layer simultaneously pass through the phase change at the melting temperature $T_{M}$. Equation 1 becomes :

$$
\rho c_{P f} V \frac{d T_{f}}{d t}=\rho c_{P f} q_{c}\left(T_{m}-T_{m+1}\right)+N \Phi_{i}
$$

According to a simplifying assumption melting-front is considered to be concentric and equations for $\Phi_{\mathrm{i}}$ are the same than for crystallisation. During the melting process, heat transfer is undergoing upon natural convection and conduction. Only heat conduction 
equation is kept into consideration but an apparent thermal conductivity [10] is used in order to take into account the natural convection.

\subsubsection{Validation of the model}

The accuracy of the model has already been confirmed by comparison between the experimental results and the results given by the numerical simulation for controlled conditions of flow rate and of inlet temperature concerning the charge mode and the discharge mode.

For actual systems, the inlet temperature of the fluid in the tank is not controlled but depends on the refrigerating capacity upon the charge mode and depends on the useful refrigerating capacity upon the discharge mode. Furthermore the flow rate can vary. The simulation of an air conditioning plant, whose results have been already presented in a previous paper [11], has also given good results.

\section{Design and modelling of the different components of the plant.}

\subsection{The turbine}

The selected turbine is a land turbo-alternator used for Combined Heat and Power generation. It can run with oil or natural gas; last one is retained for a higher output of the machine. Figure 2 illustrates the relationship between ambient air temperature and mechanical power for the studied gas turbine. The mechanical power is of $1115 \mathrm{~kW}$ with an ambient air temperature of $15^{\circ} \mathrm{C}$ (ISO conditions, $60 \%$ relative humidity) and power drop is $9 \mathrm{~kW}$ when the temperature of the air increases $1^{\circ} \mathrm{C}$. So, with $40^{\circ} \mathrm{C}$, the power is only $890 \mathrm{~kW}$ involving, compared to the standard conditions $\left(15^{\circ} \mathrm{C}\right)$, a fall of $225 \mathrm{~kW}$ that is to say $20 \%$ of the capacity. The electric output is equal (taking into account the efficiency of the alternator) to $96 \%$ of the mechanical power. 


\subsection{The exchanger}

The exchanger incorporates cooling coils (cooling battery). Cooling coils have copper tubes and continuous aluminium fins. Its characteristics are related to the size of the turbo-alternator. It is designed to cool, from $40^{\circ} \mathrm{C}$ to $15^{\circ} \mathrm{C}, 6 \mathrm{~kg} \mathrm{~s}^{-1}$ air (maximum mass flow rate in the turbine) with a relative humidity of $60 \%$ by means of glycol water whose temperature varies along the exchanger from $2^{\circ} \mathrm{C}$ to $7^{\circ} \mathrm{C}$. The value $15^{\circ} \mathrm{C}$ is selected for air temperature because it corresponds to the standard conditions of turbine operation. The air pressure drop caused by the device must be limited so that the turbine mechanical power should not be reduced. The selected exchanger whose pressure drop is $120 \mathrm{~Pa}$ only induces a mechanical power drop of $0.2 \%$. The air and the coolant are arranged in counterflow. The company which designs and manufactures the exchanger does not give us access to the code of simulation of the coils. On the other hand it enabled us to make use of their selection aid software. The software determines the state of the two fluids on the outlet side of the exchanger since the state and the flow rate of the two fluids at the inlet are defined. From software results a simplified model has been established which permits us to calculate the required total heat capacity of the battery. Heat fluxes are then introduced into the general modelling of the installation. It is necessary to distinguish the wet mode with vapour condensation on the exchange surface from the dry mode [12]. The exchanged flux in dry mode is given by: $P=U S \Delta T_{L m}$ with $U$ the overall heat transfer coefficient, $S$ the total external surface and $\Delta T_{L m}$ the log mean temperature difference between the two fluids. The heat flow exchanged between the coolant and the wet air during the vapour condensation can be calculated by : $P=K S \Delta H_{L m}$ with $\mathrm{K}$ the total enthalpy exchange coefficient and $\Delta H_{L m}$ the log mean difference in enthalpy between airstream and surface defined as follows 
with the assumption that the saturated air temperature on the external battery wall is similar to the internal fluid temperature :

$$
\Delta H_{L m}=\frac{\left(H_{a i}-H_{f o}\right)-\left(H_{a o}-H_{f i}\right)}{\ln \left(\frac{H_{a i}-H_{f o}}{H_{a o}-H_{f i}}\right)}
$$

From the simulation results given by the manufacturer's software, we can, thanks to the heat power calculation relations presented above, determine the value of the coefficient $K$ in wet mode and the value of the coefficient $U$ in dry mode.

These coefficients only practically depend on the glycol water flow rate and the air flow rate into the exchanger. We have established a correlation giving the values of $K$ and of $U$ only depending on the flow rates. The effectiveness - Number of Transfer Units (NTU) - method enables us to calculate the exchanged heat transfer rate by knowing only the characteristics of the fluids (air and glycol water) at the inlet of the battery. $P=E q_{a i r} C p_{a i r}\left(T_{a i}-T_{f i}\right)$ dry mode $P=E q_{a i r}\left(H_{a i}-H_{f i}\right)$ wet mode

The effectiveness $E$ is a function of the fluid flowing mode, of the heat capacity ratio

$$
\begin{aligned}
& R=\frac{q_{a i r} C p_{\text {air }}}{q_{f} C p_{f}} \text { and of the NTU number with : } \\
& N T U=\frac{K S}{q_{\text {air }}} \text { for the wet mode or } N T U=\frac{U S}{q_{\text {air }} C p_{\text {air }}} \text { for the dry mode. }
\end{aligned}
$$

Although the geometry of the exchanger is complex, the selected relation of the effectiveness, valid for a counter flow exchanger, gives very good results. The heat transfer rate value makes it possible to determine the outlet temperatures of the fluids, either directly for the coolant, or via the humid air enthalpy for the air :

$$
P=q_{f} c_{P f}\left(T_{f o}-T_{f i}\right) \text { or } P=q_{a i r}\left(H_{a o}-H_{a i}\right) .
$$

\subsection{Refrigerating machine}


The refrigerating machine which consumes a part of the electric output supplied by the turbine is dimensioned to charge the tank storage during the hours of electric overproduction i.e. during the night for our case. The capacity is considered to be sufficient if storage is complete, that is to say, in practice, when glycol water comes out the tank with $-10^{\circ} \mathrm{C}$. The available duration for the charge mode is about 8 hours. To simulate the refrigerating machine characteristics, supposed compression type, their variation according to the operating conditions are taken into account. The temperature of condensation is supposed to be constant. The temperature of evaporation decreases as the charge mode proceeds, involving a performances drop which is simulated by relations suggested by a refrigerating machines manufacturer. For a glycol water temperature of $0^{\circ} \mathrm{C}$ and an ambient temperature of $40^{\circ} \mathrm{C}$, the realistic efficiency, i.e. the ratio of the refrigerating power to the electric power input, was estimated to 2.3.

\section{Choice of the parameters and results}

\subsection{Climate}

Simulation is tested on one standard day, hot and wet in New Delhi in August (see Figure 3) during which the temperature varies from $26^{\circ} \mathrm{C}$ to $37^{\circ} \mathrm{C}$ and the relative humidity from $50 \%$ to $80 \%$. It should be noted that the hot and wet air will be more difficult to cool and this choice will make it possible to dimension the cooling system for the most constraining case.

\subsection{Histogram of the electric load}

The electric production of the turbine must meet the electric requirement of the plant. For the tested case we consider a traditional type of electric load (see Figure 4), corresponding to a diurnal activity of which the maximum $(1150 \mathrm{~kW})$ is provided by the 
turbine for an outside temperature of $11^{\circ} \mathrm{C}$. On figure 4 the required power and the selected turbine power are superimposed. So we can see that electric turbine output which varies according to the ambient temperature is insufficient during the hot hours of the day.

\subsection{Results}

Figure 5 presents, versus time, the comparison between the required power and the turbine power. The latter depends on the air cooling and is represented on this figure for three sizes of storage tank $\left(34.4 \mathrm{~m}^{3} ; 41.7 \mathrm{~m}^{3} ; 51.5 \mathrm{~m}^{3}\right)$. These curves must be analysed by taking into account the turbine power without inlet air cooling, indicated on figure 4 . The simulation starts on $7 \mathrm{~h} 00$. The storage tank is supposed completely charged. The refrigerating machine is off and only storage is required for the inlet air cooling. From 7h30 the ambient conditions are such as the turbine alone cannot meet the required power. An inlet air cooling is necessary and until $17 \mathrm{~h} 30$ the three sizes of tank make it possible to solve the problem. From this date only the tank of $51.5 \mathrm{~m}^{3}$ volume provides a sufficient cooling in order to enable a correct operation of the plant. This volume corresponds to a cylindrical tank $2.5 \mathrm{~m}$ diameter and $10.5 \mathrm{~m}$ high.

At the end of the day, electric requirement is decreasing but it is necessary to add the refrigerating machine consumption for storage charging. This one can start up only if the available power is sufficient i.e. if the difference between the power provided by the turbine and the required power is equal to the refrigerating machine electric consumption. Around $23 \mathrm{~h} 30$ the refrigerating unit starts. Three different curves according to the tank size are obvious again. The highest required power naturally corresponds to the largest volume since the available duration for storage is the same one in any case. The electric output consumed by the refrigerating machine are, for each 
case and for a glycol water temperature of $0^{\circ} \mathrm{C}: 173 \mathrm{~kW}$ for $34.4 \mathrm{~m}^{3} ; 209 \mathrm{~kW}$ for 41.7 $\mathrm{m}^{3} ; 256 \mathrm{~kW}$ for $51.5 \mathrm{~m}^{3}$.

Figure 6 allows, thanks to the representation of the variations of some temperatures, to know the state of the storage tank all along the day. Only results concerning the tank of $51.5 \mathrm{~m}^{3}$ volume are represented. The temperatures of ambient air and of inlet air turbine are compared. At $7 \mathrm{~h} 30$ the air is cooled from $27^{\circ} \mathrm{C}$ to $11^{\circ} \mathrm{C}$ to make it possible for the turbine to provide the required power. At $21 \mathrm{~h} 30$ cooling is not needed any more and the two temperatures are identical.

The change of glycol water temperatures at the inlet and at the outlet of the tank makes it possible to distinguish the charge mode from the discharge mode. As long as cooling is needed, i.e. until $22 \mathrm{~h}$, the inlet temperature of the tank is the same one as that which comes out the exchanger. The selected exchanger has a good efficiency and the two outlet temperatures (air and glycol water) are practically identical. It is the discharge mode starting from a tank initially with $-10^{\circ} \mathrm{C}$. The distinct plateau at $0^{\circ} \mathrm{C}$ for the outlet temperature is corresponding to the PCM melting point. The second significant phase of required power (from $18 \mathrm{~h}$ to $21 \mathrm{~h}$ ) is supplied, thanks to a more significant flow in the tank, by actuating the mixing three-ways. Consequently, for the tank outlet temperature increases and tends to the inlet temperature, that is the end of the discharge mode. When cooling is not needed any more and when the refrigerating machine cannot start yet (between $22 \mathrm{~h}$ and $23 \mathrm{~h} 30$ ), there is no flow in the tank and the temperatures into the tank remain stationary.

The charge mode starts at $23 \mathrm{~h} 30$ and the flow in the tank is reversed. The coldest temperature is now the inlet temperature for the tank. The observation of the outlet temperature highlights the supercooling phenomenon. One can notice, indeed, that the temperature plateau which corresponds to the PCM crystallisation occurs at a 
temperature lower than $0^{\circ} \mathrm{C}$ while the melting stage is strictly located at $0^{\circ} \mathrm{C}$. The outlet temperature drop after the plateau indicates that it is the end of the phase change. When the temperature reaches $-10^{\circ} \mathrm{C}$ the tank is estimated to be entirely charged.

\section{Conclusion}

The association of a refrigeration storage in order to carry out the inlet air cooling enables the designer to select a lower capacity turbine. The benefit is linked to the investment of a refrigerating machine and a storage system. Only an economic survey adapted to each case can determine the appropriateness of the use of refrigeration storage to cool turbine inlet air. Indeed, the potential of using thermal energy storage (TES) in the form of ice or chilled water to cool gas turbine inlet air was evaluated for a remote oil field location in the Sultanate of Oman using local hourly typical meteorological year weather data. The authors [13] found that TES whether seasonal, partial, or full storage is not a viable option for the considered location.

On the other hand the modelling which makes it possible to dimension the cooling system when the climate and the electric requirement versus time are known is the first step essential to the decision-making. The modelling could also simulate operations close to that studied in this paper where cooling would be supplied by the use of refrigeration storage but also at the same time by a direct refrigerating production. In this way various strategies of control of installation could be defined.

The studied case is the most unfavourable since the climate is hot and wet. A hot and dry climate is also penalising for the turbine operation but the dry air cooling requires less power. So the size of the tank and the refrigerating machine are smaller involving a lower investment. 


\section{Acknowledgements}

We thank the Cristopia company, the Turbomeca company and the Ciat company which have contributed to the definition of the plant and gave access to the design features of the various elements which appear in this study.

\section{References}

[1] M.M. Alhazmy, Y.S.H. Najjar, Augmentation of gas turbine performance using air coolers, Applied Thermal Engineering 24 (2004) 415-429

[2] M. M. Alhazmy, R. K. Jassim, G. M. Zaki, Performance enhancement of gas turbines by inlet air-cooling in hot and humid climates, Int. J. Energy Res. 30 (2006) $777-797$

[3] M. Ameri, H. R. Shahbazian, M. Nabizadeh, Comparison of evaporative inlet air cooling systems to enhance the gas turbine generated power, Int. J. Energy Res. 31 (2007)1483-1503

[4] M. Ameri, S. H. Hejazi, K. Montaser, Performance and economic of the thermal energy storage systems to enhance the peaking capacity of the gas turbines, Applied Thermal Engineering 25 (2005) 241-251

[5] S. M. Hasnain, Review on sustainable thermal energy storage technologies, Part II: cool thermal storage, Energy Conversion and Management 39 (11) (1998) 1139-1153 [6] J.P Bédécarrats, J.P. Dumas, Etude de la cristallisation de nodules contenant un matériau à changement de phase en vue du stockage par chaleur latente, Int. J. Heat Mass Transfer 40 (1) (1997) 149-157

[7] J.P Bédécarrats, F. Strub, B. Falcon, J.P. Dumas, Phase-change thermal energy storage using spherical capsules : performance of a test plant, Int. J. Refrig 19(3) (1996) 187-196. 
[8] T. Kousksou, J.P. Bédécarrats, J.P. Dumas, A. Mimet., Dynamic modelling of the storage of an encapsulated ice tank, Applied Thermal Engineering 25 (10) 1534-1548. [9] V. Alexiades, A.D. Solomon, Mathematical Modeling of Melting and Freezing Processes.» In: Hemisphere Publishing Corporation,1993, 126-152.

[10] S. Fukusako et M. Yamada, Recent advances in research on melting heat transfer problems, 10th Int Heat Transfer Conf, Brighton, (1) (1994) 313-331.

[11] F Strub, J.P. Bédécarrats, B. Falcon, J.P. Dumas, Synthesis of the studies on a cold storage process using encapsulated phase change material (in French), Actes du Colloque Interuniversitaire Franco-Québécois, (1997) 347-352 (1997)

[12] Y. Xia, A. M. Jacobi, Air-side data interpretation and performance analysis for heat exchangers with simultaneous heat and mass transfer: Wet and frosted surfaces, International Journal of Heat and Mass Transfer 48 (2005) 5089-5102.

[13] Y. H. Zurigat, B. Dawoud, J. Bortmany, On the technical feasibility of gas turbine inlet air cooling utilizing thermal energy storage, Int. J. Energy Res. 30 (2006) 291-305

\section{Nomenclature}

$\mathrm{c}_{\mathrm{P}}$ specific heat, $\mathrm{Jkg}^{-1} \mathrm{~K}^{-1}$

$\mathrm{h}$ heat transfer coefficient nodule - fluid, $\mathrm{W} \mathrm{m}^{-2} \mathrm{~K}^{-1}$

$\mathrm{H}_{\mathrm{ai}}$ air enthalpy at the inlet of the battery, $\mathrm{J}$

$\mathrm{H}_{\mathrm{ao}}$ air enthalpy at the outlet of the battery, $\mathrm{J}$

$\mathrm{H}_{\mathrm{fi}}$ saturated air enthalpy at the inlet of the battery at the inlet fluid temperature, $\mathrm{J}$

$\mathrm{H}_{\mathrm{fo}}$ saturated air enthalpy at the inlet of the battery at the outlet fluid temperature, $\mathrm{J}$

$\mathrm{k}_{\mathrm{s}}$ thermal conductivity of solid PCM, $\mathrm{W} \mathrm{m}^{-1} \mathrm{~K}^{-1}$

$\mathrm{k}_{\mathrm{p}}$ thermal conductivity of the envelope of the nodule, $\mathrm{W} \mathrm{m} \mathrm{m}^{-2} \mathrm{~K}^{-1}$ 
$\mathrm{K}$ enthalpy exchange coefficient, $\mathrm{W} \mathrm{m}^{-2} \mathrm{~K}^{-1}$

$\mathrm{L}_{\mathrm{F}}$ latent heat of fusion of PCM, $\mathrm{J} \mathrm{kg}^{-1}$

$\mathrm{P}$ heat transfer rate of the exchanger, $\mathrm{W}$

$\mathrm{q}_{\mathrm{c}} \quad$ volumetric fluid flow quantity into the tank

$\mathrm{q}_{\text {air }}$ mass flow rate of the air, $\mathrm{kg} \mathrm{s}^{-1}$

$\mathrm{q}_{\mathrm{f}}$ mass flow rate of the fluid in the exchanger, $\mathrm{kg} \mathrm{s}^{-1}$

$\mathrm{r}_{\mathrm{S}}(\mathrm{t})$ inner radius of the solid PCM, $\mathrm{m}$

$r_{e}, r_{i}$ external and inner radius of the nodule, $m$

S surface of the battery, $\mathrm{m}^{2}$

$\mathrm{S}_{\text {nod }}$ surface of the nodule, $\mathrm{m}^{2}$

$\mathrm{T}_{\mathrm{M}}$ PCM melting temperature, ${ }^{\circ} \mathrm{C}$

$\mathrm{T}_{\mathrm{f}}(\mathrm{t}) \quad$ fluid temperature into the tank, ${ }^{\circ} \mathrm{C}$

$\mathrm{T}_{\mathrm{ai}}$ inlet air temperature of the battery, ${ }^{\circ} \mathrm{C}$

$\mathrm{T}_{\mathrm{ao}}$ outlet air temperature of the battery, ${ }^{\circ} \mathrm{C}$

$\mathrm{T}_{\mathrm{fi}}$ inlet fluid temperature of the battery, ${ }^{\circ} \mathrm{C}$

$\mathrm{T}_{\text {fo }}$ outlet fluid temperature of the battery, ${ }^{\circ} \mathrm{C}$

$\mathrm{U}$ overall heat transfer coefficient battery, $\mathrm{W} \mathrm{m}{ }^{-2} \mathrm{~K}^{-1}$

$\mathrm{V}$ volume of the fluid in a mesh, $\mathrm{m}^{3}$

Greek symbols

$\boldsymbol{\Delta}_{\mathrm{Lm}} \log$ mean temperature difference between the two fluids

$\Delta \mathbf{H}_{\mathrm{Lm}} \log$ mean difference in enthalpy between the two fluids

\$ Heat transfer rate exchanged by a nodule i, W

Qr,t) PCM temperature in a nodule at the radius $\mathrm{r}$ and the time $\mathrm{t},{ }^{\circ} \mathrm{C}$

$\rho \quad$ fluid density, $\mathrm{kg} \mathrm{m}^{-3}$ 
ß $\quad$ solid PCM density, $\mathrm{kg} \mathrm{m}^{-3}$

Abbreviation

PCM Phase Change material

\section{Figure Captions}

Figure 1: Schematic diagram of the plant.

Figure 2: Effect of the inlet air on the studied gas turbine performance

Figure 3: Temperature and relative humidity versus time for one day on August in New Delhi (India).

Figure 4: Comparison between the electric output required and the electric capacity provided by the turbine without cooling.

Figure 5: Comparison between electric capacity provided by the turbine for 3 different sizes of tank and the electric load.

Figure 6: Variation, versus time, of the ambient temperature, the inlet air temperature of the turbine and the water glycol temperatures at the inlet and at the outlet sides of the tank. 
Figure 1: Schematic diagram of the plant.

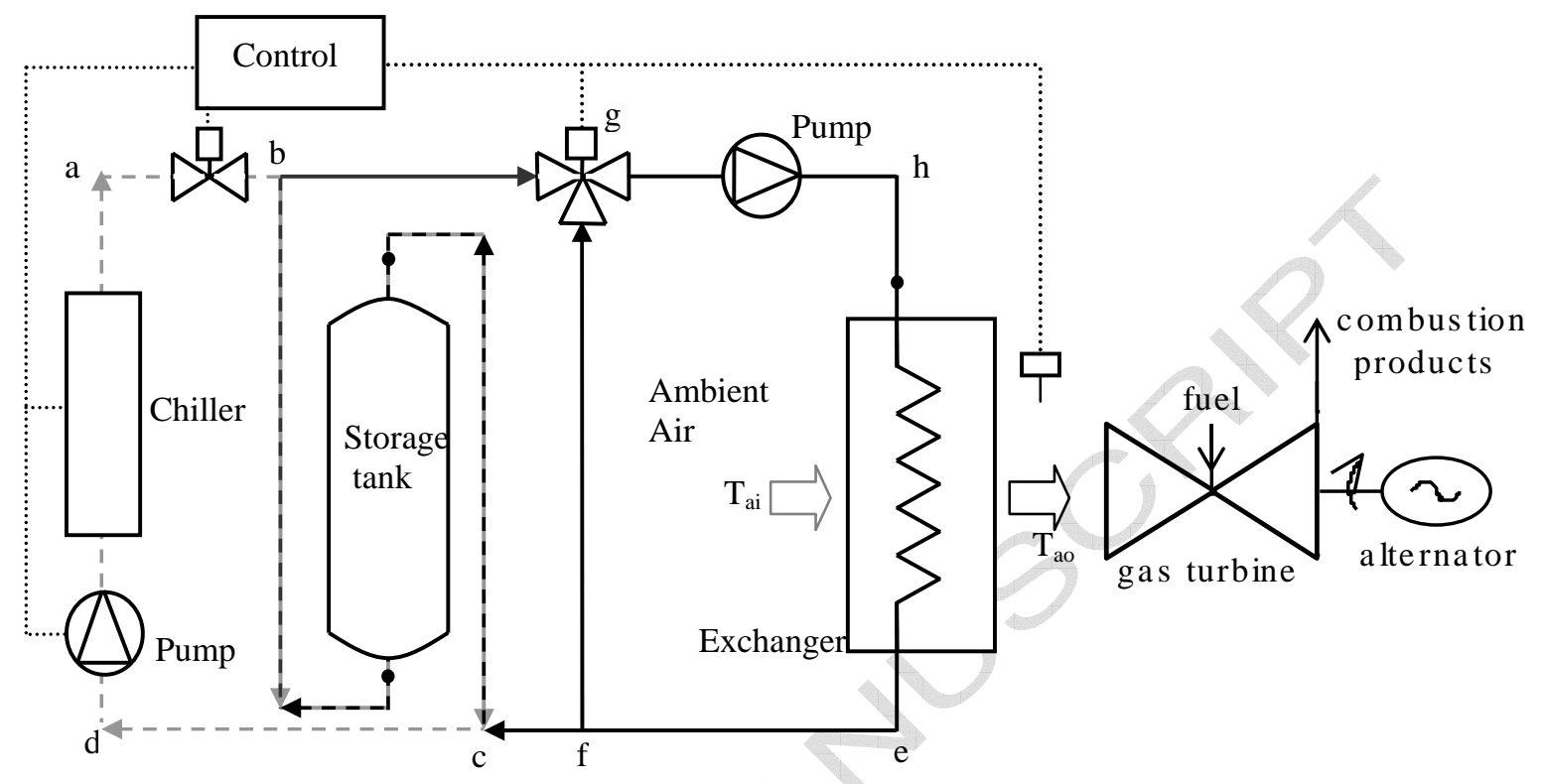

abcd charge loop

bghefc discharge loop with partial flow fg to control temperature $T_{\text {as }}$ 
Figure 2: Effect of the inlet air on the studied gas turbine performance

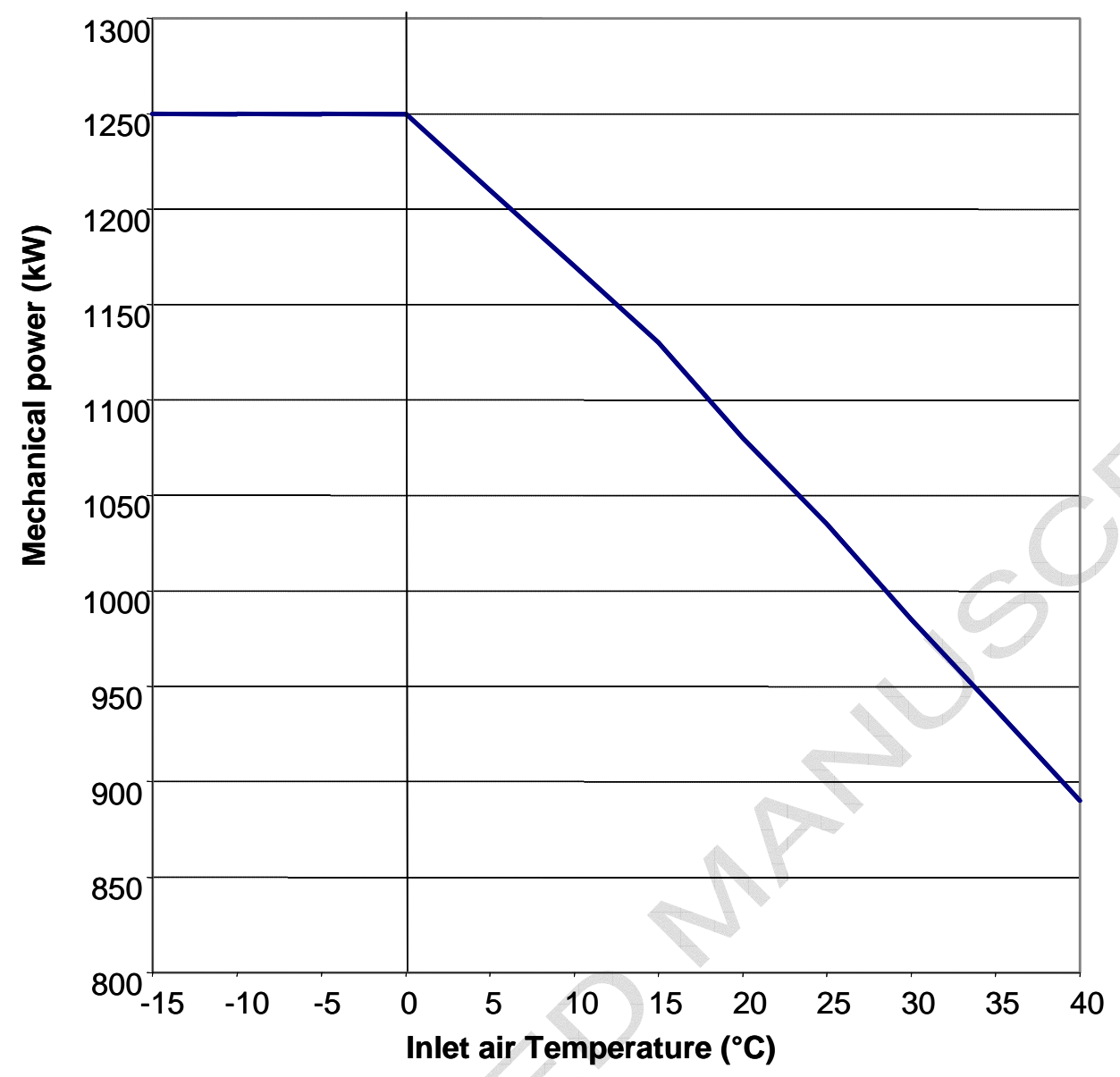


Figure 3: Temperature and relative humidity versus time for one day on August in New Delhi (India).

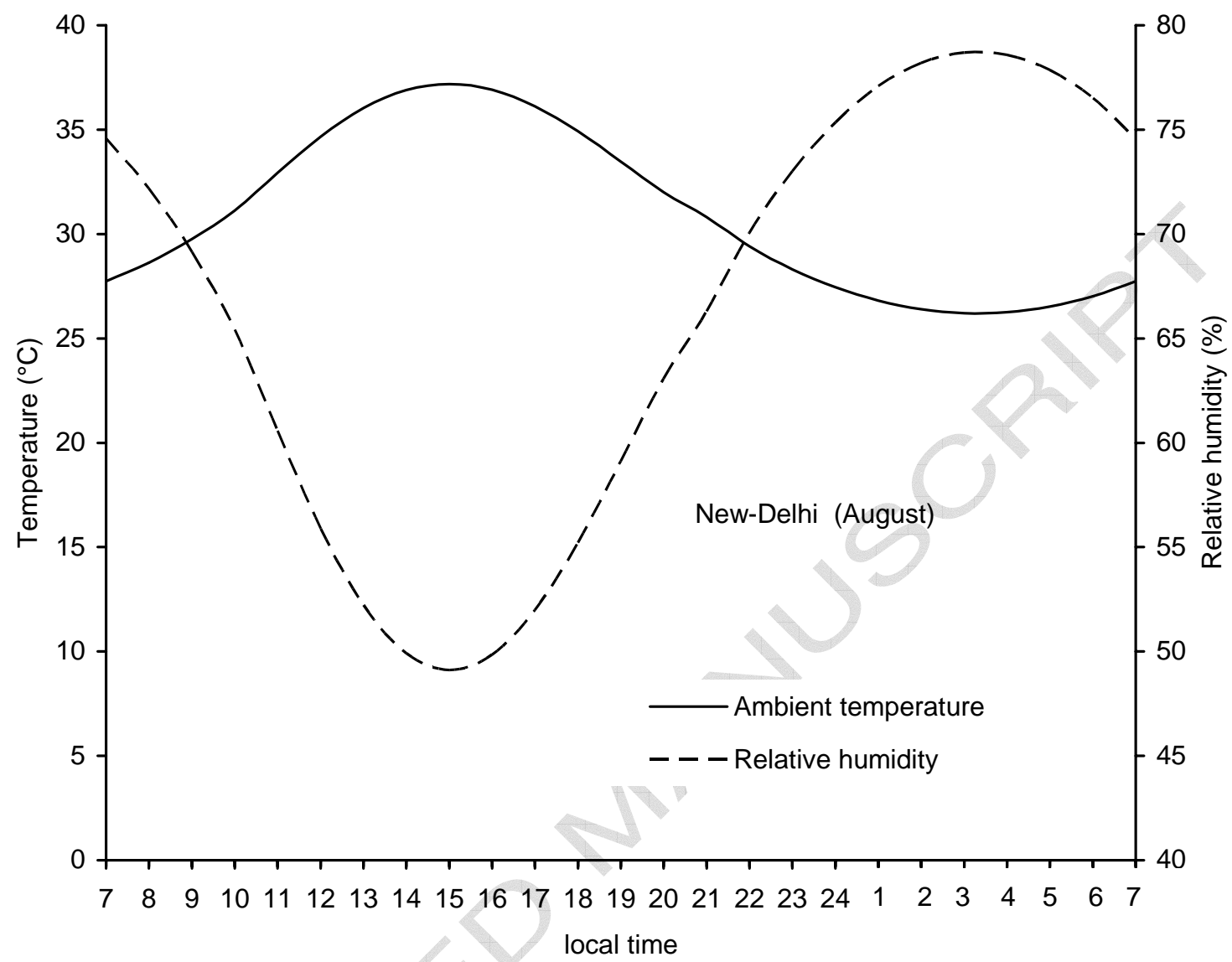


Figure 4: Comparison between the electric output required and the electric capacity provided by the turbine without cooling.

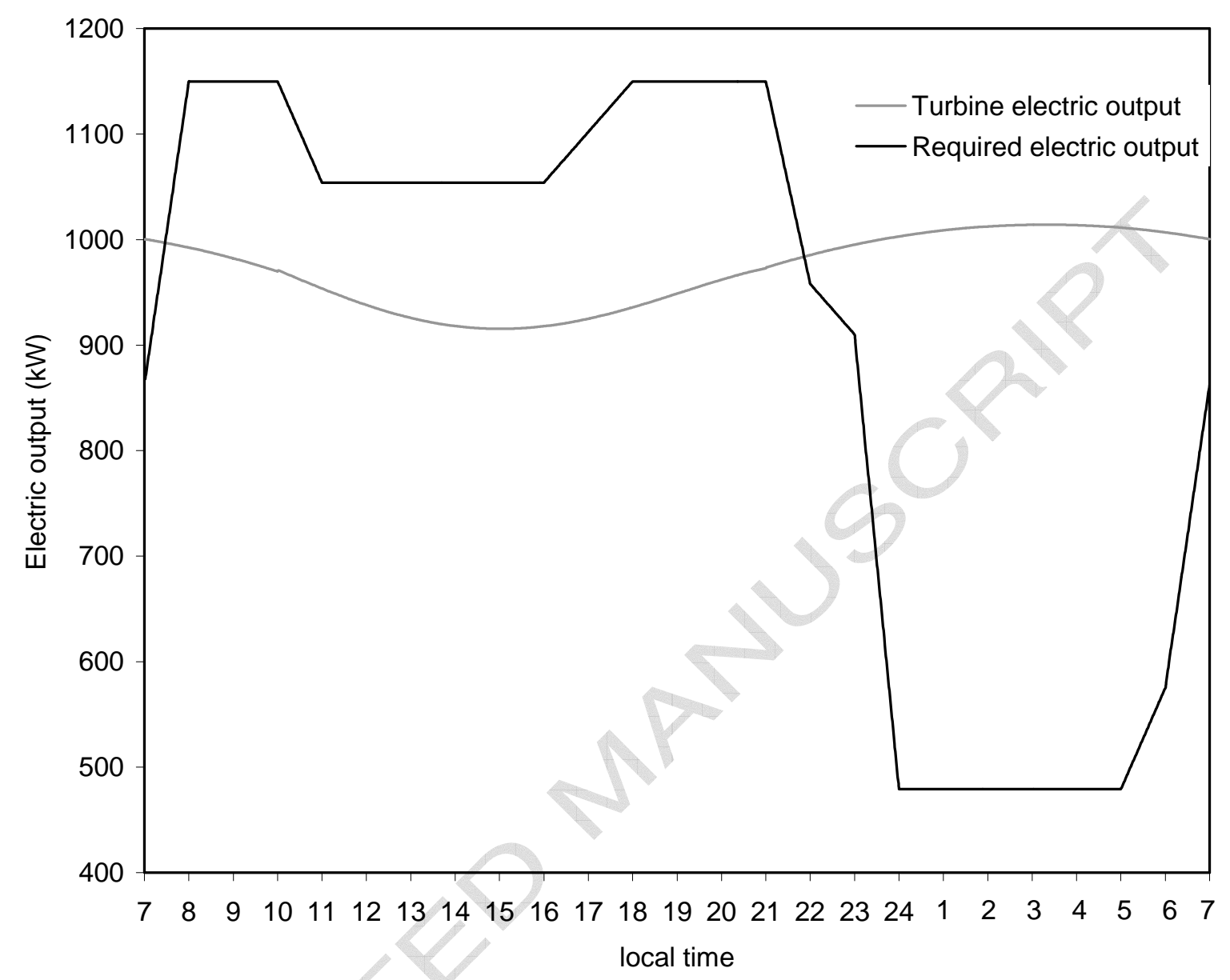


Figure 5: Comparison between electric capacity provided by the turbine for 3 different sizes of tank and the electric load.

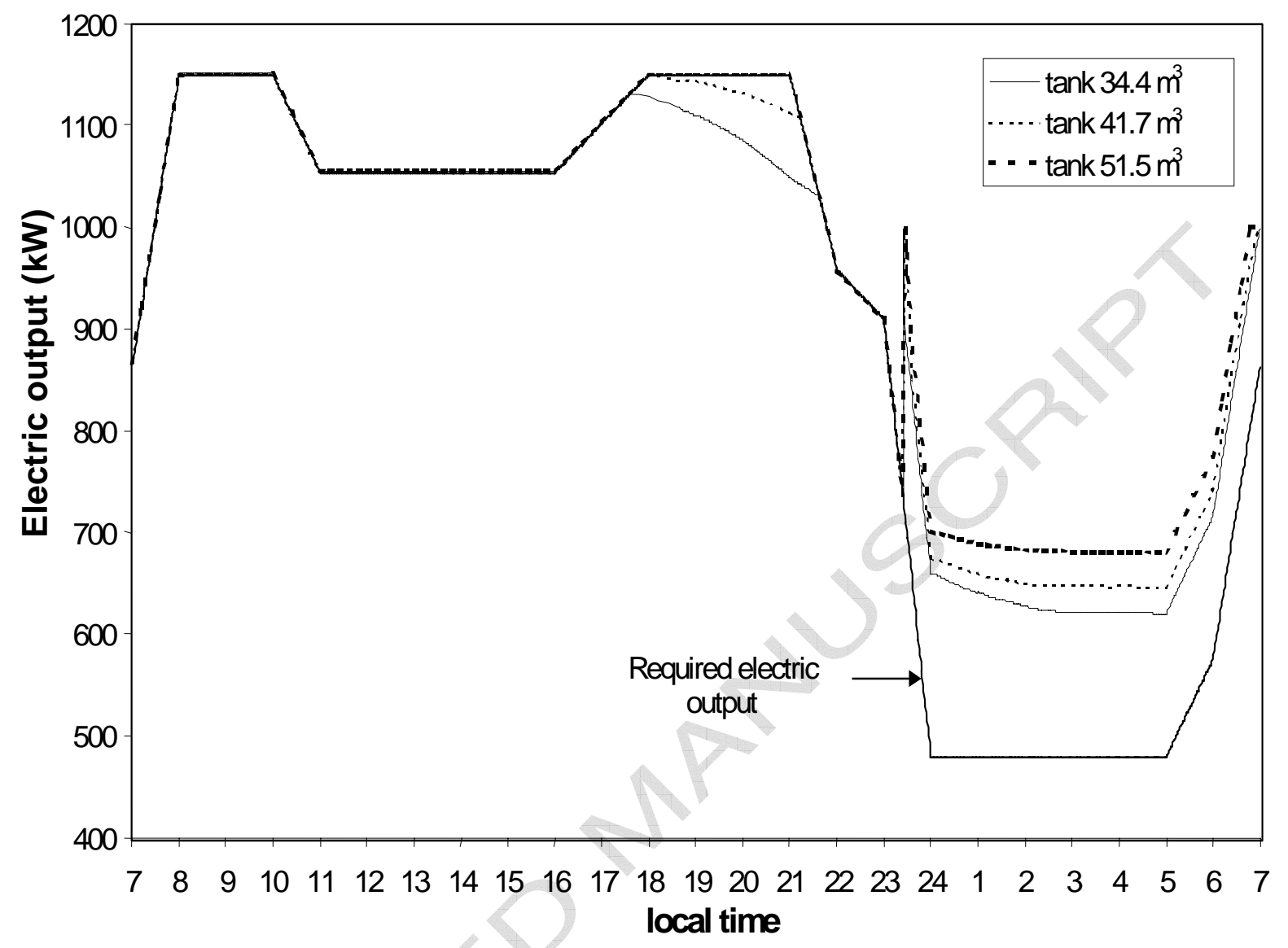


Figure 6: Variation, versus time, of the ambient temperature, the inlet air temperature of the turbine and the water glycol temperatures at the inlet and at the outlet sides of the tank.

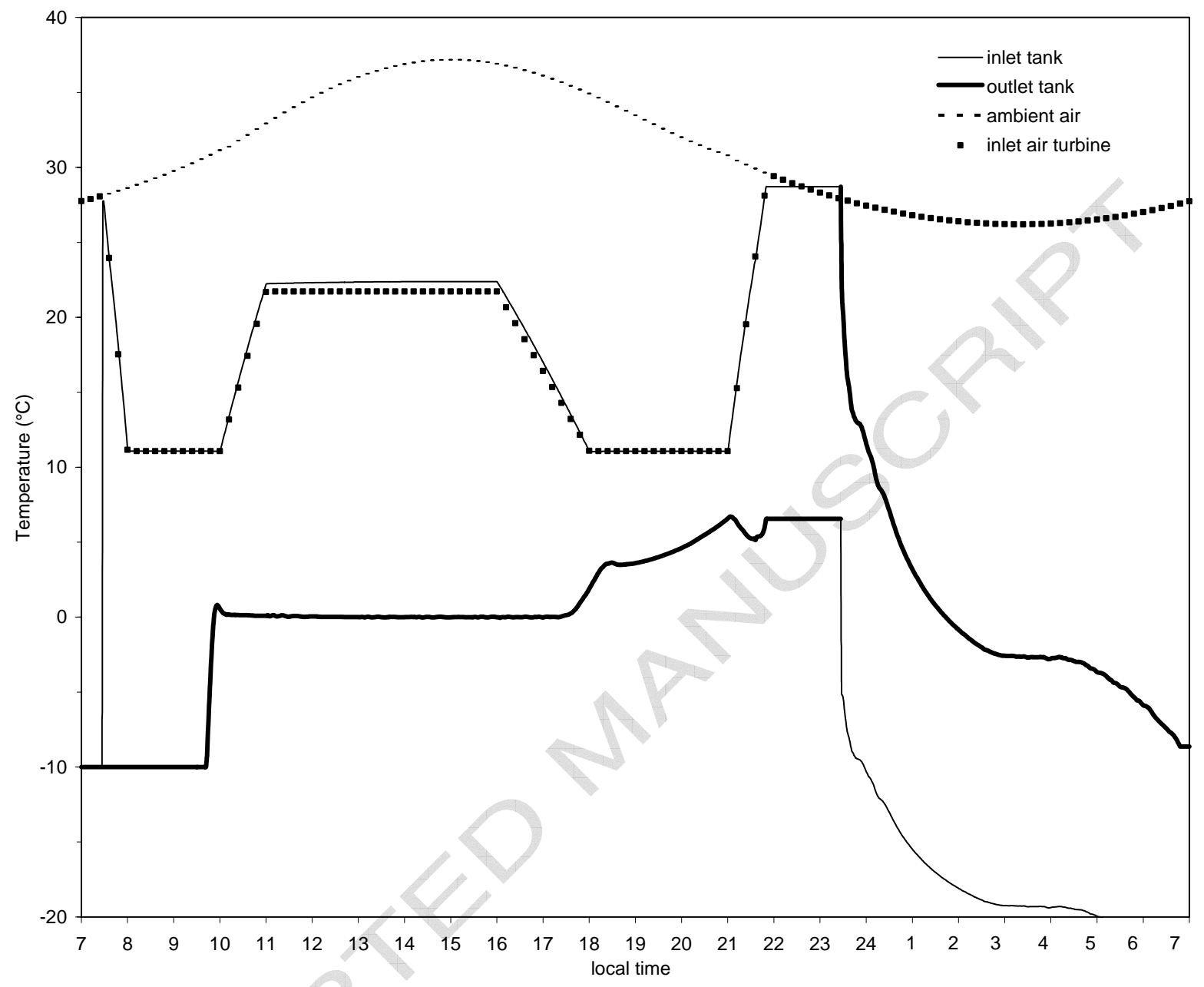

